\title{
PROJETO DE EXTENSÃO CINESPORTE: CORPO, ESPORTE E EDUCAÇÃO
}

\author{
PROJECT OF EXTENSION CINESPORTE: BODY, SPORTS AND EDUCATION \\ PROYECTO DE EXTENSIÓN CINESPORTE: CUERPO, DEPORTE Y EDUCACIÓN
}

\author{
Marcus Vinicius Simões Campos \\ Universidade Estadual de Campinas, UNICAMP. E-mail: camposmvs@gmail.com \\ Wagner Wey Moreira \\ Universidade Federal do Triângulo Mineiro, UFTM. E-mail: weymoreira@uol.com.br \\ Bruno da Silva Conceição \\ Universidade Federal do Triângulo Mineiro, UFTM. E-mail: bruno.silva_educa@outlook.com \\ Regina Simões \\ Universidade Federal do Triângulo Mineiro, UFTM. E-mail: rovigatisimoes@uol.com.br
}

\section{RESUMO}

O cinema, como um dos símbolos de inovação da modernidade, possibilita a circulação do conhecimento, a difusão de novas experiências e valores culturais, a reconstrução do passado e aguça a imaginação. Com base nesta reflexão, este relato de experiência tem como objetivo divulgar um projeto de extensão que desenvolve debates a partir de temas relacionados com a área da Educação Física, da Educação e dos Esportes presentes na cinematografia existente denominado Cinesporte. Este projeto é proposto pelo Núcleo de Estudos e Pesquisas em Corporeidade e Pedagogia do Movimento (NUCORPO) da Universidade Federal do Triângulo Mineiro (UFTM) e tem como foco instigar o senso crítico da comunidade para os fenômenos esporte, corpo e educação, e compreender que outras formas de divulgação do conhecimento também podem auxiliar na formação e atuação profissional.

PALAVRAS-CHAVE: Esporte. Cinema. Projeto de Extensão.

\section{ABSTRACT}

Cinema, as one of the symbols of innovation of modernity, enables the circulation of knowledge, the diffusion of new experiences and cultural values, the reconstruction of the past and sharpens the imagination. Based on this reflection, this experience report aims to disseminate an extension project that develops debates based on themes related to an area of Physical Education, Education and Sports present in the existing cinematography called Cinesporte. This project is proposed by the Núcleo de Estudos e Pesquisas em Corporidade e Pedagogia do Movimento (NUCORPO) of the Federal University of Triangulo Mineiro (UFTM) and aims to instigate the community's critical sense for sports, body and education phenomena and to understand that other forms of knowledge dissemination can also assist in professional performance and formation.

KEYWORDS: Sport. Cinema. Extension Project.

\section{RESUMEN}

El cine, como uno de los símbolos de innovación de la modernidad, posibilita la circulación del conocimiento, la difusión de nuevas experiencias y valores culturales, la reconstrucción del pasado y aguza la imaginación. Con base en esta reflexión, este relato de experiencia tiene como objetivo divulgar un proyecto de extensión que desarrolla debates a partir de temas relacionados con el área de la Educación Física, de la Educación y de los Deportes presentes en la cinematografía existente denominada Cinesporte. Este proyecto es propuesto por el Núcleo de Estudios e Investigaciones en Corporeidad y Pedagogía del Movimiento (NUCORPO) de la Universidad Federal del Triángulo Minero (UFTM) y tiene como foco instigar el sentido crítico de la comunidad hacia los fenómenos deportivos, cuerpo y educación, y comprender que otras formas de divulgación del conocimiento también pueden auxiliar en la formación y actuación profesional. 


\section{INTRODUÇÃO}

A constante presença das tecnologias em nossos dias faz com que sejamos envoltos por inúmeras formas de comunicação audiovisual e, consequentemente, a dinâmica educativa acompanha este processo, cedendo seus espaços às inovações desenvolvidas ao longo do tempo. Uma destas formas de comunicação audiovisual é o cinema, que data sua primeira aparição no ano de 1895 na França.

Ele possui significativa inserção social pois ao mesmo tempo é um veículo de comunicação e de expressão como também produtor de um repertório de imagens, de vocabulário, de gostos, de consumos e de memórias (ZANINI; WEBER, 2010).

O cinema como um dos símbolos de inovação da modernidade, também possibilita a circulação do conhecimento, a difusão de novas experiências e de valores culturais. Assistir a um filme permite a reconstrução do passado bem como revisitar eventos ocorridos ou imaginados (OLIVEIRA, 2006). No Brasil, como material educativo, tem ganhado força dentro das organizações educacionais como as escolas e as universidades nas últimas décadas.

Na Educação Básica, por exemplo, há a obrigatoriedade com base na Lei n. 13.006 de 26/6/2014, de que sejam exibidos filmes de produção nacional nas escolas, em pelo menos duas horas mensais, o que gera a necessidade de que a universidade ofereça espaços para que esta experiência possa ser vivenciada e posteriormente repassada na ação profissional. A sociedade contemporânea que é cercada por apelos visuais, tem na imagem um meio de adquirir e/ou produzir conhecimento, o que significa dizer que compreender aquilo que vemos, suscita um olhar mais crítico ao que nos é apresentado a todo momento em diferentes esferas do cotidiano do ser humano. Educar o olhar do indivíduo para esta apreciação mais significativa da obra é uma meta da universidade ou melhor dizendo: "Educar pelo cinema ou utilizar o cinema no processo escolar é ensinar a ver diferente. É educar o olhar. É decifrar os enigmas da modernidade na moldura do espaço imagético." (CARMO, 2003, p. 5).

No âmbito acadêmico o cinema já é estudado há muito tempo por inúmeros filósofos, sociólogos, críticos de arte e cineastas. Dada a sua acessibilidade, nestes tempos da rede global de comunicação, o cinema contribui com pesquisas científicas oriundas de diversas áreas do conhecimento tanto nas humanas como Filosofia, Arte e Educação, quanto nas biológicas como Enfermagem, Medicina e Educação Física. 
Neste trabalho, apresentamos as contribuições do projeto de extensão Cinesporte, vinculado ao Núcleo de Estudos e Pesquisa em Corporeidade e Pedagogia do Movimento NUCORPO, associado aos Programa de Pós-graduação em Educação e ao Programa de Pósgraduação em Educação Física, ambos desenvolvidos na Universidade Federal do Triângulo Mineiro - UFTM. Com seu público alvo centrado nos estudantes de Educação Física, atualmente o projeto atende discentes de diversos cursos da UFTM e conta com a participação de toda comunidade acadêmica representada também por professores e funcionários.

Desde sua gênesis, os líderes do NUCORPO pautaram esta proposta de projeto de extensão com a finalidade de associar filmes com temáticas relevantes que pudessem estar presentes no universo da Educação Física, da Educação e dos Esportes. Claro que isto não pode ser considerado como originalidade, levando-se em consideração que outras instituições acadêmicas também caminham nesta perspectiva como: a Universidade Federal do Mato Grosso do Sul - UFMS, Universidade Estadual de Campinas - UNICAMP, Universidade Estadual de São Paulo - USP, Universidade Estadual da Paraíba - UEPB, Universidade Federal do Rio de Janeiro - UFRJ, entre outras.

A partir da organização das evidências recolhidas ao longo dos quatro anos de realização do projeto Cinesporte, este relato de experiência tem como foco divulgar a inciativa de um projeto de extensão que desenvolve debates a partir de temas relacionados com a área da Educação Física, da Educação e dos Esportes presentes na cinematografia existente.

\section{POR QUE UM PROJETO DE EXTENSÃO COM CINEMA?}

Em nossos dias o cinema está disponível através de aparelho remoto, computador ou televisão, esta última tanto na forma aberta quanto na fechada, sendo presente na vida de muitas pessoas. Contudo, o entendimento de cinema nos escapa se o reduzirmos a um simples movimento de imagens com a função única de nos entreter.

Bernardet (2000) nos lembra o fato de ser a indústria cinematográfica uma complexa rede internacional, por isso mesmo detentora de poderes sobre seus aficionados. Mais complexas que a tecnologia e a economia responsáveis pelo cinema acontecer, é importante não esquecermos o fato de todas as estórias e as histórias contadas através das telas partem de intenções, culturas, sociedades e ideologias, dirigindo-se a todos nós com uma miríade de 
mensagens travestidas de entretenimento. Talvez este seja um elemento central na utilização do cinema em harmonia com a educação, o de ele poder trazer aos olhares dos estudantes, com sua capacidade única de arte e reprodução inigualável do real, o humano que todos somos arremessados em suas inúmeras contingencias.

Merleau-Ponty (2004) aponta preocupações sobre os sentidos que a arte possa ter em nossas percepções. Por um lado, se entrarmos no seu universo com uma postura prática e utilitária, derivada do hábito da vida cotidiana, podemos nos esquecer da vida ou da existência em si. Por outro lado, continua o pensar do filósofo, pode estar na arte a possibilidade de permitir a redescoberta do mundo.

Talvez o cinema, enquanto uma das formas de manifestação artística, possa se enquadrar no cenário vislumbrado pelo filósofo. As palavras de Xavier (2008, p. 14-15) destacam esta questão pois:

\footnotetext{
De um lado, cinema incorpora aquela dimensão formadora própria às várias formas de arte que cumprem um papel decisivo de educação (informal e cotidiana); de outro, ele pode se inscrever de forma mais sistemática no processo educativo, seja pelo uso de qualquer gênero de filme (ficção, documentário) em sala de aula, com interação direta com a fala do professor, seja pela produção daquela modalidade especial a que se deu o nome de "filme educativo", esse que supostamente se estrutura como ato comunicativo que apresenta, de um modo ou de outro, uma demarcação, uma metodologia de ensino, um princípio pedagógico, voltados para um domínio específico do conhecimento ou para o adestramento para uma prática (o vídeo tornou tal modalidade um item de grande sucesso comercial).
}

Importante salientar nesse processo que o registro da imagem no momento do acontecimento se constituiu de uma trajetória de buscas, tentativas e experimentos que perpassa por muitos anos (COSTA, 2006), constituindo um novo recurso para contar histórias, mostrar uma visão de mundo, um contexto da sociedade, uso e costumes, ideologias, retratar uma realidade, entre outras. Um filme não pode ser considerado como um processo neutro ou nem ingênuo e a análise fílmica é um exercício de entendimento da obra, do espaço imagético a partir do olhar e das experiências vividas de cada um, que podem ser entrecruzados com outros olhares e outras visões de mundo (CARVALHO, 2006; VANOYE, LETÉ, 1994). A imagem fascina, atrai olhares e sua utilização pode gerar os mais diferentes sentimentos e as mais distintas emoções. 
O cinema possui obras de diversos gêneros, que compreendem várias faixas etárias, por isso, conseguem, por meio da emoção e ao mesmo tempo da razão, perspectivar a realidade, dialogando e ampliando a visão de mundo daqueles que se apropriam dele (NAPOLITANO, 2006). Na contemporaneidade, muitas vezes se tem mais acesso às práticas sociais pela arte/imagem do que pela vivência direta. No caso do esporte, por exemplo, ele é mais assistido pela televisão do que praticado, no entanto, é preciso contribuir para ampliar o olhar sobre o fenômeno esportivo, sobre o corpo e sobre a própria educação.

Podemos afirmar que as relações entre cinema e esporte, assim como cinema e corpo, estão entre as linguagens mais acessadas no decorrer do século $\mathrm{XX}$, não somente nos seus espaços específicos (as salas de projeção e os estádios), como também em função da ação dos meios de comunicação, que nelas investiram por se tratarem de produtos de grande penetração popular (RUIZ, 2002).

Com base nesta premissa, ao longo dos últimos quatro anos, uma farta programação de filmes e uma grande oferta de documentários que tem como mote o esporte, como também questões relacionadas ao corpo/corporeidade ou a educação, temas pilares do NUCORPO, foram reproduzidos e debatidos. Em um curso de formação acadêmica em que se discute o esporte não só como uma prática, mas como um fenômeno social, é essencial oferecer propostas que possam refletir para além dos muros da universidade.

A relação entre projetos de extensão e o cinema organizados por cursos de Educação Física também se estende à pesquisa, pois esta parece ganhar espaço através de relatos e reflexões em congressos, livros ou revistas especializadas da área da Educação Física nos últimos anos. Publicações recentes podem ser destacadas, como é o caso dos trabalhos realizados pelo curso de Educação Física da UFMS (SOUZA, LANA, SILVA, 2015), pelo Grupo de Pesquisa e Extensão Corpo, Educação e Linguagens da UEPR (COSTA, DANTAS, 2016) e pelo Centro de Estudos Socioculturais do Movimento da USP (SAURA, ZIMMERMANN, 2016). Acreditamos que tais iniciativas, mesmo que ainda tímidas no cenário nacional, colaboram para o fomento à pesquisa sobre os temas presentes nos cursos de Educação Física e sua relação com o cinema.

\section{O CINESPORTE}


Presente na UFTM desde 2014, o Cinesporte tem como intuito diminuir a distância entre as áreas da Educação Física, da Educação e dos Esportes com as demais áreas de conhecimento por meio da linguagem do cinema. Assim, os objetivos do projeto são: instigar o senso crítico da comunidade para os fenômenos esporte, corpo e educação, e compreender que outras formas de divulgação do conhecimento também podem auxiliar na formação e atuação profissional.

Com uma dinâmica de um filme apresentado na última terça-feira de cada mês, o projeto se instala no Cine Urbano Salomão, espaço arrendado pela própria universidade. Os encontros geralmente têm duração de quatro horas e os filmes são escolhidos em função da votação dos integrantes do NUCORPO nas reuniões finais e iniciais de cada semestre, para que seja possível a organização e a divulgação adequada de cada sessão.

$\mathrm{Na}$ exibição dos filmes há a presença dos membros do grupo de estudos e deste são definidos dois debatedores, escolhidos por estarem mais próximos aos temas estudados no grupo de pesquisa, na intenção de que os debates que ocorrem ao final da seção, sejam melhor aproveitados pelos espectadores e debatedores.

Para sua escolha, os filmes são enquadrados preferencialmente nas três categorias que alicerçam o projeto: o esporte, o corpo e a educação. Contudo, este primeiro filtro não exclui outros temas como dança, saúde, qualidade de vida, história, arte, cultura, entre outros. Para melhor ilustrar os títulos que compõem a história do Cinesporte podemos destacar campeões de bilheteria como: Coach Carter, de Thomas Carter, debatendo temas como educação e esporte; Menina de Ouro, de Clint Eastwood, incitando debates sobre esporte, corpo, preconceito e gênero; Um Sonho Possível, de John Lee Hancock, que oferece a oportunidade de debate sobre desigualdade social, esporte universitário, educação e racismo; Capitão Fantástico, de Matt Ross, e sua crítica à educação escolar instrumental e utilitária; The Program, de Stephen Frears revelando um indetectável esquema de doping com a conivência das instituições esportivas ou A Garota Dinamarquesa, de Tom Hooper, e os debates contemporâneos sobre corpo, gênero e sexualidade.

Uma vez que os temas esporte, corpo e educação são os mais recorrentes, é natural que o próprio grupo de estudos tenha uma posição quanto suas concepções. Por mais que compreendidos como realidades separadas, os debates centram-se na desmistificação de 
verdades cristalizadas e reducionismos, incentivando a reflexão sobre tais fenômenos, como também atenta para a necessidade de sua compreensão integrada.

Neste sentido, a própria escolha por um projeto com o cinema é uma tentativa de que, a partir do envolvimento com as imagens, o processo de formação possa destinar-se a corpos racionais, sensíveis e vivos na sua existência, história e cultura (MERLEAU-PONTY, 2011). Pois o ser humano "[...] não aprende somente com sua inteligência, mas com seu corpo e suas vísceras, sua sensibilidade e sua imaginação.” (MOREIRA et al., 2006, p. 140).

Assim como o corpo, o esporte também é um tema central das discussões do NUCORPO, ocupando lugar privilegiado nos debates. Contudo recorremos a Moreira e Simões (2016) para desmistifica-lo de seu reducionismo, defendendo o conhecimento e a prática de modalidades esportivas como um fenômeno sociocultural, somente compreensível através corpo enquanto corporeidade em sua facticidade.

Associamos os autores anteriormente referidos com Bento (2013, p. 82-83) quando enfatiza:

O desporto é o um palco onde entra em cena a representação do corpo, das suas possibilidades e limites, do diálogo e relação com a nossa natureza interior e exterior, com a vida e o mundo. Quer se diga de crianças, jovens, de adultos e idosos, de cadentes e deficientes, de rendimento ou recreação, o desporto é em todos os casos instrumento de concretização de uma filosofia do corpo e da vida. Constitui uma esperança para a necessidade de viver.

Finalmente destacamos a posição de Rezende (1990). O autor recoloca a educação como aprendizagem da cultura, rompendo a ainda hegemônica concepção de uma aprendizagem racional centrada apenas em conteúdo sem significância para os alunos, enaltecendo uma aprendizagem de corpos entrelaçados no contexto social enquanto experiência educativa, uma vez que não há educação ou pensamento sem presença, contexto, circunstância e experiência.

Durante os quatro anos de projeto, reconhecemos que existem inúmeros títulos de filmes capazes de trazer ao debate os temas apresentados anteriormente de forma ainda mais crítica e profunda, não necessariamente suscetíveis à lógica das produções dos grandes estúdios de Hollywood. Porém, nestes primeiros anos de projeto optamos por filmes amplamente divulgados e com considerável impacto na população, na busca de atingirmos o máximo de público possível e, consequentemente, enriquecer o debate e a formação. 
Neste sentido, também é possível relatar a pluralidade no debate no que se refere à diversidade de cursos da UFTM. Além de graduandos em Educação Física, já se fizeram presentes às últimas terças-feiras de cada mês discentes dos seguintes cursos:

Tabela 1 - Cursos de graduação da UFTM beneficiados pelo Cinesporte desde 2014

\begin{tabular}{lr|lrl}
\hline \multicolumn{2}{c}{ Exatas } & \multicolumn{2}{c}{ Biológicas } & \multicolumn{2}{c}{ Humanas } \\
\hline Engenharia $\quad$ Ambiental, & Biomedicina, & Ciências & Geografia, & Letras, \\
Engenharia de & Alimentos, & Biológicas, Enfermagem, & Licenciatura em Educação no \\
Engenharia Elétrica, Física e & Fisioterapia, & Medicina, & Campos, & História, \\
Química. & Nutrição e Educação Física. & Psicologia, Serviço Social e \\
& & Terapia Ocupacional. \\
\hline
\end{tabular}

Total: 20

Dos 28 cursos de graduação oferecidos pela UFTM, três estão presentes no campus de Iturama/MG, resultando um total de 25 cursos de graduação presenciais oferecidos nos campi do município de Uberaba/MG. Como mostra a Tabela 1, desde 2014 um total de 20 cursos de graduação das três grandes áreas de atuação já se beneficiaram com o Cinesporte, mesmo com a presença predominante dos alunos do curso de Educação Física.

Como o NUCORPO é um laboratório/grupo de estudos e pesquisa ligado aos mestrados em Educação Física e em Educação, muitos dos mestrandos desses cursos também participam das discussões dos filmes apresentados, incluído aqui diversos dos professores alocados na pósgraduação da UFTM.

Ao longo destes quatro anos ininterruptos de projeto, 38 filmes já foram exibidos, tendo um máximo de 54 espectadores em uma só exibição. Ao todo, mais de 700 presenças já foram assinadas nas listas do Cinesporte, por pessoas dos diferentes cursos de graduação, pósgraduação e comunidade interna e externa à UFTM, o que evidencia a pluralidade nos debates e seu consequente impacto na formação das pessoas envolvidas de alguma forma com o projeto. Mediante à heterogeneidade presente no Cine Urbano Salomão, o projeto não somente oferece uma possibilidade de lazer, mas um espaço fértil para o compartilhamento de experiências, 
pontos de vistas e questionamentos, advindos de diversas áreas do conhecimento, enriquecendo a formação de todos os envolvidos.

\section{CONSIDERAÇÕES FINAIS}

O projeto de extensão Cinesporte, para além do auxílio na formação dos discentes da UFTM, busca criar oportunidades para problematizar a realidade e, ao mesmo tempo, através das análises das projeções dos filmes provocar e mesmo inspirar jovens para se tornarem agentes de transformação da realidade quando esta se apresenta de forma opressiva em que, por exemplo, ética e moral são desprezadas. Daí ser um empreendimento educativo de importância atual, cumprindo a preocupação de Merleau-Ponty (2004) de retornar à experiência vivida.

Também faz parte das preocupações dos integrantes do NUCORPO, sem abandonar a importância de uma formação acadêmica em que estejam presentes o domínio instrumental e técnico, buscar formas de alertar os graduandos da UFTM para a necessidade de uma educação universitária mais humana no lidar com os problemas cada vez mais complexos da sociedade atual. Isto só será possível se empreendermos uma educação ética, a qual deve ser individual, cívica e centrada no gênero humano (MORIN, 2013).

\section{REFERÊNCIAS}

BENTO, J. O. Desporto: discurso e substância. Belo Horizonte: Instituto Casa da Educação Física/UNICAMP - Centro de Estudos Avançados - Coleção CEAv Esporte, 2013.

BERNARDET, J. C. O que é cinema. São Paulo: Brasiliense, 2000.

CARMO, L. O cinema do feitiço contra o feiticeiro. Revista Ibero Americana, n. 32, 2003. Disponível em: http://rieoei.org/rie32a04.htm. Acesso em 05 mai 2017.

CARVALHO, M. S. Cinema novo brasileiro. In: MASCARELlO, F. (Org). História do cinema mundial. Campinas: Papirus, 2006, p. 35-48. 
COSTA, F. C. Primeiro cinema. In: MASCARELLO, Fernando (org). História do cinema mundial. Campinas: Papirus, 2006, p. 60-71.

COSTA, E. M. B; DANTAS, E. R. Corpo, dança e cinema: a extensão universitária como locus da formação de professores. Holos, ano 32, v. 4, p. 413-422, 2016.

MERLEAU-PONTY, M. Conversas - 1948. São Paulo: Martins Fontes, 2004.

MERLEAU-PONTY, M. Fenomenologia da percepção. 4. ed. São Paulo: Editora Martins Fontes, 2011.

MOREIRA, W.W.; SIMÕES, R. Educação Física, esporte e corporeidade: associação indispensável. In: MOREIRA, W.W.; NISTA-PICCOLO, V. (org). Educação Física e esporte no século XXI. Campinas: Papirus, 2016, p. 133-152.

MOREIRA, W.W et. al. Corporeidade aprendente: a complexidade do aprender a viver. In: MOREIRA, W. W. (org). Século XXI: a era do corpo ativo. Campinas: Papirus, 2006, p. 137150 .

MORIN, E. A via: para o futuro da humanidade, Rio de Janeiro: Bertrand Brasil, 2013.

NAPOLITANO, M. Como usar o cinema na sala de aula. 4. ed. São Paulo: Contexto, 2006.

OLIVEIRA, B. J. Cinema e imaginário científico. História, Ciências, Saúde, Manguinhos, v. 13 (suplemento), p. 133-50, 2006.

REZENDE, A.M. Concepção fenomenológica da educação. São Paulo: Cortez/Autores Associados, 1990.

RUIZ, J. L. La unión de dos ofertas culturales del siglo XX. Sevilha. 2002. Disponível em:http://www.festivaldesevilla.com, acesso em 20 jan 2016.

SAURA, S. C.; ZIMMERMANN, A. C. Cinema e corpo. São Paulo: Pró-Reitoria de Cultura e Extensão Universitária - USP/Editora Laços, 2016.

SOUZA, M..L.G.; SILVA, L. L. G.; SILVA, J.V. Cinesporte no curso de Educação Física da Universidade Federal de Mato Grosso do Sul. Revista Brasileira de Educação Fisica e Esporte. São Paulo, v. 29, Supl 9, p.60-60, 2015.

VANOYE, F.; LÉTE, A. G. Ensaio sobre a análise fílmica. Campinas: Papirus, 1994. XAVIER, I. Um cinema que "educa" é um cinema que (nos) faz pensar. Educação \& Realidade, v. 33, n. 1, p. 13-20, 2008. 


\section{Triângulo}

www.seer.uftm.edu.br/revistaeletronica

ZANINI, M.C.; WEBER, L. I. Cinema sem pipoca, mas com debater: reflexões acerca do uso do cinema no ensino e extensão em Antropologia. Revista Eletrônica de Extensão, Florianópolis, v. 7, n. 9, p. 87-99, 2010. 